\title{
Changing Identities in Taiwan under Ma Ying-jeou
}

\author{
Jean-Pierre Cabestan
}

Since the beginning of Taiwan's democratization in the late 1980s, identities on the island have fundamentally changed. Then, most citizens of the Republic of China (ROC), Taiwan's official name, considered themselves as Chinese, and only a minority considered themselves as Taiwanese. The latter segment of the society was concentrated in and around the newly formed and legalized opposition group, the Democratic Progressive Party (DPP). Today, the situation has reversed: fewer than 5 percent of ROC citizens regard themselves as Chinese, between 60 and 70 percent see themselves as Taiwanese, and the rest claim a double identity, both Taiwanese and Chinese. In other words, all political forces, including the Kuomintang (KMT), which for a long time enjoyed a dominant and in reality one-party status and dreamed of reunifying China under its rule, have "Taiwanized." However, many ROC citizens would readily admit that they are politically Taiwanese but culturally Chinese, suggesting that, as in many modern societies, multiple identities are getting more common and do not necessarily generate social or political tensions. Only the most militant of the proindependence, or "Green," Taiwanese would try to draw a clear line between Chinese and Taiwanese cultures, emphasizing the distinctiveness and specificity of the latter.

At the same time, after Ma Ying-jeou's election as Taiwan president and the KMT's return to power in 2008, Ma, the KMT, and what is called in Taiwan the "Blue camp" (fanlanjun, a coalition of the KMT, the People First Party [PFP], the New Party [CNP], and the Minkuotang [MKT]) embarked on an attempt to restore a more traditional Chinese and ROC political and cultural identity, both as a way to facilitate the rapprochement that they had initiated with the People's Republic of China (PRC) and as a strategy to weaken their political opponents, the 
independence-leaning forces called the "Green camp" (fanlüjun) in general and the DPP in particular. Simultaneously, economic and social relations across the Taiwan Strait have rapidly developed, multiplying interactions between ROC and PRC citizens.

These two trends can nurture opposite consequences: they can help bridge the gap between mainland Chinese and Taiwanese and persuade the latter that, after all, not much separates them from the former; but, they can also help expose or underscore differences between both societies, and, in a protective reaction observed elsewhere, convince most Taiwanese that while they may share with PRC citizens some cultural features, such as the (written) language, they belong to a very different socioeconomic environment and polity.

My hypothesis is that the Taiwanese political or civic identity, closely linked to the island's democratization and democratic life, will continue to consolidate. The Spring 2014 Sunflower Movement, the KMT's landslide defeat in the late November 2014 local elections, and, more importantly, Tsai Ing-wen's victory and the DPP's return to power (and for the first time control of the Legislative Yuan) since 2016 have all illustrated this trend. Simultaneously, we are witnessing a diversification of ways to be Taiwanese, leading some to associate their identity with the local culture, the building of a new Taiwanese nation, and even the quest for formal independence from China and others to accommodate Taiwanese people's identity with a democratized, sovereign, and de facto independent ROC on Taiwan.

\section{CHANGING POLITICAL IDENTITIES IN TAIWAN BEFORE 2008: A BRIEF OVERVIEW}

We start this section with some broad and well-known trends: National Chengchi University's Election Study Center, one of the most respected and reliable opinion poll organizations on the island, tells us that in June 201659.3 percent of the interviewees considered themselves Taiwanese, as opposed to 17.6 percent in 1992 and 43.7 percent in 2008; 3.4 percent of them see themselves as Chinese (25.5 percent in 1992 and 4.1 percent in 2008); and 33.6 percent of them view themselves as both Taiwanese and Chinese (46.4 percent in 1992 and 44.7 percent in 2008). ${ }^{1}$

The first, most obvious conclusion from this survey is that Taiwanese identity now dominates the society, completely sidelining Chinese identity. The second is that, stable and dominant until 2008, the group of Taiwanese claiming a double identity has started to decrease since Ma Ying-jeou was elected, raising some doubts about the efficacy of the KMT's attempt to "resinicize" the island. But the third conclusion-often overlooked-is that in 1992, at the beginning of Taiwan's democratization, people claiming a Chinese identity were already a minority that would weaken rather rapidly in the middle of the same decade, becoming the smallest group, behind the people who saw themselves as only Taiwanese, as early 
as 1995 (20.7 percent against 25.0 percent). In other words, when Taiwan was still at the dawn of democracy, nearly half of the island population had a double identity and almost two-thirds saw themselves either as both Taiwanese and Chinese or as simply Taiwanese.

It is true that, while informative, this kind of survey has a major weakness: it does not make any distinction between cultural and political identities. ${ }^{2}$ However, from the beginning the emergence of Taiwanese identity has been both a political or civic and a cultural phenomenon. It originated as a response to the February 28 Massacre (an uprising against the KMT-led government in Taiwan in 1947 that was violently suppressed by the ROC military and resulted in an estimated ten thousand deaths) as well as the KMT's policy forbidding and punishing Taiwanese students' use of their native language at school (mainly Hokkien or Minnan, known in Taiwanese as Tâi-oân-ô or Tâi-gi $)^{3}$ and more broadly to the disconnect, imposed by the civil war in 1949, between the ROC's "one-China" principle or legal fiction and the Taiwanese geocultural reality. While political activists like Peng Ming-min claimed as early as the 1960 s a Taiwanese identity closely linked to their democratization demands, in the 1970s the rise of this identity was also a cultural phenomenon of "nativization" (bentuhua), particularly in literature and arts, that took shape in reaction to the KMT-inspired dominant traditional Chinese culture and cultural production. In the political realm, in spite of martial law, the KMT itself had no other choice but to get "Taiwanized" ( 66 percent of its members were Taiwanese in 1986), a process that would reach its leadership in 1986 (when mainlander domination of its powerful Central Standing Committee dropped to 55 percent, then two years later dropped to 48 percent), just before President Chiang Ching-kuo legalized the DPP and lifted martial law (1987), initiating Taiwan's democratic transition. In the local and (partial) national elections that have been allowed to take place since the early 1950 (with an increase of the seats for national elections starting in 1969), opposition (or dangwai) candidates were more and more often inclined to use Taiwanese as opposed to Mandarin during their campaigns, contributing to promoting a politico-cultural identity that the KMT then continued, if not to ignore, to actively downplay. And since the 1970s, in Taiwan's scholarly and intellectual community and later in the general public, there has been a growing awareness of the ethnic diversity of the island, leading to the construction of the concept of "subethnic" groups (zuqun) to characterize its major components: the Hoklo (fulao) or South Fujian immigrants (7o percent of the population), the Hakka (kejiaren, 15 percent), the mainlanders (waishengren, 13 percent), and the aborigines (shandiren and after democratization the various groups of yuanzhumin, 2 percent). ${ }^{4}$ Over the same period, more Taiwanese have given themselves another definition of their Chineseness, accepting the epithet huaren or ethnic Chinese but not zhongguoren (Chinese), which has become clearly associated with PRC citizenship. In other words, cultural identity and cultural 
identity debates in Taiwan are closely linked to democratization and have always been highly politicized. As a result, for a long time Taiwanese surveys on identity have been understood by both the interviewees and the public to have a dominant political or, to be more accurate, civic dimension: in other words, they have been indicative of the emergence of a new Taiwanese national "civic identity."

Another issue, more contentious, is whether there is a direct relationship between identity and nation, between political identity and national identity, and between Taiwanese identity and the quest for Taiwan's de jure or de facto independence. This relationship is obvious: as Christopher Hughes has argued, a "civic nationalism" has taken shape in Taiwan. ${ }^{6}$ But the nature and content of the nation that has been under construction since democratization and even since 1949 and the split of China into two separate states can still be understood differently. Taiwanese civic and national identities sometimes converge, notably for those who favor formal independence or a permanent separation from China, but sometimes diverge, for those who prefer to keep the ROC constitutional envelope or "order," to use an expression proposed by President Tsai Ing-wen in her inauguration speech in May 2016, or even the "one-China" (ROC) principle as defined in the KMT's inspired formula "one China, differing interpretations." ${ }^{\text {" And as we shall }}$ see below, the gap between the aspiration to build a distinct and new Taiwanese nation and the geopolitical reality and political options that can be contemplated is widening. Hence the constant ambiguities and limitations of Taiwan nationalism. ${ }^{9}$ Said differently, in Taiwan more than in any other place and because of wellknown international constraints, the relationship between identity and nationalism has remained complicated. ${ }^{10}$

Identity politics have been widely studied in Taiwan. This chapter is not the place to present or review this rich literature. Suffice it to say that, because of Taiwan's unusual history, diverse subethnic composition, ill-recognized statehood and international status, and long domination by the 1.5 million mainlanders or "outsiders" (waishengren, who arrived in 1945-50, as opposed to Taiwan's "natives" or benshengren), democratization has had a direct impact both on the central role played by identity politics and on the rapid consolidation of Taiwanese civic - and to a large extent national-identity. Consequently, since the early 1990s, identity politics has influenced all parties. For the KMT, it has induced a painful metamorphosis, playing a role in the new internal fractures that took shape under Lee Teng-hui (1988-2000) between the then "mainstream faction" (zhuliupai), which supported the president's Taiwanization process, and the "nonmainstream faction" (feizhuliupai), which included leaders as General Hau Pei-tsun, prime minister from 1990 to 1993 . The latter wished to keep the party's strong Chinese identity and mainland traditions (such as the "Huangpu spirit," a spirit of unity and cooperation among parties and factions for the good of the country as a whole). ${ }^{11}$ One of the disputes of this period concerned the revision of history textbooks and the 
publication of the series "Get to Know Taiwan" (Renshi Taiwan). ${ }^{12}$ In his first term as KMT chair, Lee Teng-hui kept a balance between his desire to promote Taiwan's identity, uniqueness, and statehood and the need to compromise with the more conservative leaders of his party. ${ }^{13}$ Launched in 1993, Taiwan's United Nations bid was a good example of the middle road then adopted: Taiwan proposed to return to the UN under the name of ROC rather than Taiwan, as the DPP would have preferred. And in its 1994 white paper on cross-Strait relations, the Taiwanese government stuck to the idea that there was only one Chinese nation (guojia) while asking Beijing to recognize that it was divided into two "political entities" (zhengzhi shiti).

But after his reelection by the whole Taiwanese electorate in 1996, Lee gradually moved away from this path: in 1999, he advocated a (quasi) two-state approach to cross-Strait relations that clearly indicated a priority given to the building of a Taiwanese nation distinct not only from the PRC but also in reality from China. In doing so, he was trying both to rein in the DPP's growing popularity by coopting its issue and to move the KMT in the direction he wished. This change affected many KMT leaders, including Ma Ying-jeou, who declared in 1998 as he was running for Taipei mayor that, in spite of his mainland origin, he was a "new Taiwanese" (xin Taiwanren). In any event, it is interesting to note that the proportion of ROC citizens who defined themselves as only Taiwanese increased from 25 percent in 1995 to 39.6 percent in 1999, while Chinese identity dropped even lower (from 20.7 percent in 1995 to 12.1 percent) and dual identity remained rather stable (42.5 percent in 1995 versus 47 percent in 1999). ${ }^{14}$

The DPP underwent an easier but no less ambiguous evolution. As we know, since its establishment in 1986, the main opposition party was united around the goal to democratize Taiwan but was divided about its quest for formal independence. Then the Formosa faction (meilidao) was seen as more moderate and ready to operate within the ROC framework than the New Tide faction (xin chaoliu), which wanted to create a new nation, the Republic of Taiwan. Eventually, all DPP factions agreed in 1999 to adopt a self-determination platform that clearly denied that Taiwan was part of China but at the same time accepted faute de mieux the ROC institutions and the formula "ROC = Taiwan." In other words, by the end of the 1990s, the consolidation of Taiwanese identity favored the emergence of a new Taiwanese national identity and even nationalism that would pave the way for DPP candidate Chen Shui-bian's victory in the 2000 presidential election. ${ }^{15}$

The KMT defeat in the 2000 election constituted a turning point in Taiwan's identity politics. Once in power, Chen Shui-bian pushed the ROC's Taiwanization further: he added "Taiwan" to the ROC passport, insisted after 2002 on the island's separate statehood ("one country on each side of the Strait," or yibian yiguo) and promoted a new historical narrative and all sorts of cultural activities that underscored Taiwan's distinct identity, particularly its non-Chinese or aboriginal 
dimensions. For instance, he tried to propagate Shi Ming (Su Beng)'s interpretation of Taiwan's history as a four-hundred-year fight for freedom and independence, ${ }^{16}$ showcasing on the government website (GIO) the figure of Zheng Chenggong (or Koxinga), the Ming general who actually "sinicized" Taiwan in the seventeenth century to better resist the Qing conquest, as the forefather of this movement. He emphasized the Taiwanese character of many cultural customs or traditions that can also be found on the Chinese mainland, especially in southern Fujian, the place of origin of the Taiwanese language. And he presented Taiwan as a cultural melting pot in which each outside ingredient (Chinese, Taiwanese, aboriginal, Japanese, American) had the same level of influence. ${ }^{17}$ Made in continuity with Lee's own changes, many of these initiatives were aimed at bolstering Taiwan's sense of community and national security. ${ }^{18}$ But in retrospect, the most radical manifestations of this new Taiwanese nationalism appear to be convenient substitutes for the independence-leaning policies that Chen wanted but was unable to introduce, not only because of China's opposition and intimidation, but also because of the US government's, and particularly President George W. Bush's, growing irritation after 2003. These symbolic exaggerations triggered KMT and Blue camp accusations that Chen was "desinicizing" (qu Zhongguohua) Taiwan, precisely at the time (April 2005) of KMT chair Lien Chan's historic trip to China and resumption of party-to-party relations with the Chinese Communist Party (CCP). In a sense, it can be argued that in promoting a dark Green narrative, the Chen Shui-bian administration contributed to moving the KMT narrative to a darker Blue position. Political polarization in those years (2004-8) also played a role in the promotion of two radically opposite narratives and identities on the island. However, it is appropriate to explore the connection between the KMT's promotion of Taiwan's Chinese identity and its rapprochement policy with the PRC, and probably to look there for the main explanation of the Nationalist Party's attempt to return to its mainland roots and initial values. In any event, this short overview of Taiwan identity politics before 2008 constitutes the background of Ma Ying-jeou's attempt to restore what can be called a more traditional "ROC Chinese" identity as well as the negative reactions it has provoked in Taiwanese society, in spite of, or because of, increasing interaction between China and Taiwan.

\section{THE KMT'S NEW CHINESE NATIONALISM}

After Ma came to power in 2008, the KMT revived, to some extent, its traditional and somewhat old-fashioned Chinese nationalism, a nationalism that once again placed the unity and the future unification of the Chinese nation/race (zhonghua minzu) at the heart of its ideological discourse. This new/reborn narrative was aimed not only at denouncing and reining in what the KMT and Beijing described as Chen Shui-bian's “desinicization” policy but also at negating Lee Teng-hui's 
earlier attempted localization-Taiwanization or nativization-of the KMT and the ROC. In doing so, Ma reactivated a narrative and a discourse that had been dominant at the time of the martial law and could only revive bad memories, associated with the authoritarian period and the nondemocratic inclinations of the KMT, in the minds of older-generation Taiwanese. Although Ma did not endorse the dark Blue view, according to which Taipei, since 1949, has merely been the provisional capital of the ROC and unification should take place rapidly, he and the KMT tried to restore the centrality of Chinese culture and identity and contributed to creating tensions between their brand of Chinese nationalism and the need to cultivate local Taiwanese identity and voters. ${ }^{19}$ In other words, instead of reuniting the Taiwanese, their official objective, Ma and the KMT's new discourse created new fault lines in society.

Before his first election in 2008, Ma had published a book titled Native Spirit: The Model Story of Taiwan that challenged the "four hundred years of tragedy" narrative and emphasized the contributions of Qing administrators such as Liu Minchuan and ROC leaders such as Chiang Ching-kuo to Taiwan's modernization. ${ }^{20}$ In this book, he minimized the role of the Japanese and exaggerated the number of native Taiwanese who joined the Chinese resistance against Japan (the majority of the Taiwanese who fought in the war did it on the Japanese side). He also criticized the DPP's version of nativization as a chauvinistic and divisive attempt at desinicizing Taiwan. And after he came to power, Ma introduced a number of changes that highlighted his real intentions: in his inaugural address, he described the people on both sides of the Strait as parts of a zhonghua minzu (Chinese nation), where the concept of minzu referred to a common racial and cultural identity; he renamed Taiwan Post (Taiwan's mail service) China Post, its original name before the Chen Shui-bian presidency; while promoting democratic values, he also revived the traditional KMT discourse on the need to enhance Confucian ethics; he restored Chiang Kai-shek Memorial Hall's original name (Chen had renamed it National Taiwan Democracy Memorial Hall and hung large butterflies in it during the last year of his presidency), giving the impression of politically rehabilitating the old dictator, much to the pleasure of Chinese tourists. More importantly, he emphasized the continuity between today's Taiwan and the old ROC in terms of institutions and territories, insisting on the legal definition of the ROC as the mainland plus Taiwan. He also asserted the existence of solely "one China," according to the PRC and ROC's approved 1992 Consensus that the phrase "one China" could have differing interpretations as to which government was the legitimate representative of that China) and even, later in 2012, according to the formula "one country, two areas" (yiguo liangqu). Finally, he adopted a very assertive discourse on his country's territorial claims in both the East and the South China Sea (Diaoyutai, Spratlys), flirting with the idea of cooperating with the PRC against other claimants on these issues. ${ }^{21}$ In other words, as Stéphane 
Corcuff has indicated, Ma, a mainlander born in Hong Kong, embarked on a policy of de-Taiwanization and, as Chris Hughes has pointed out, tried in doing so to "resinicize" Taiwan in order to "justify his own legitimacy as a leader." ${ }^{2}$

The KMT's new or revived Chinese nationalism was also clearly aimed at anchoring Taiwan in the Chinese nation, bridging the gap with the PRC, opposing Taiwan independence, favoring reconciliation and eventually unification between the two sides of the Strait (with steep conditions), and legitimizing its own rapprochement policy toward Beijing. It is true that Ma Ying-jeou and his party declared in 2008 that they opposed reunification in the foreseeable future. And it is true that their strategy's objectives also included mainland China's gradual democratization, but they did not do much to that end, and they showed extreme prudence toward PRC dissidents: for instance, Ma refused to see the Dalai Lama or blind activist Chen Guangcheng when they visited the island or to issue a visa to Uighur World Congress president Rebiya Kadeer. In any event, for the Ma administration, what mattered was Taiwan's economic integration with the PRC, which they saw as the best way to boost the economy, avoid marginalization, and embrace regionalization and globalization. The coziness of KMT-CCP relations prompted increasing suspicion among Taiwanese about Ma's rapprochement policy, and not only among DPP voters. ${ }^{23}$

As we know, between 2008 and 2016, unprecedented developments took place across the Strait, including the establishment of direct air and sea links, the conclusion of twenty-three agreements, and an increasing number of Chinese tourist visits to the island (over 4.3 million in 2015). These developments clearly deepened interactions between not only both governments but also both societies. However, have they affected the Taiwanese's identity?

\section{IMPACT AND BACKLASH OF MA'S CHINESE NATIONALISM}

The answer is no, or to be more accurate yes, but not in the ways expected. If anything, as we alluded to at the beginning of this chapter, political rapprochement and growing economic integration between Taiwan and China under $\mathrm{Ma}$ have paradoxically strengthened the predominance of the Taiwanese identity. And this predominance is even stronger among youth. According to the Taiwan Brain Trust, a "Green" think tank that does produce balanced surveys and opinion polls, in August 2014, 78 percent of interviewees between ages twenty and twenty-nine see themselves as Taiwanese, as opposed to 52 percent for ages fifty to fifty-nine and 48 percent for those over seventy. Women tend feel more Taiwanese than men (67 percent compared to 54 percent for men). Educated people (with a bachelor's degree or above) also feel more Taiwanese (63 percent compared to 57-59 percent). Likewise, the support among young Taiwanese for 
independence in a three-option survey (independence, reunification, and status quo) is much higher: 44 percent for ages twenty to twenty-nine, as opposed to 18 percent for ages fifty to fifty-nine and 19 percent for over age seventy; the respective figures for status quo supporters are 45 percent, 64 percent, and 54 percent, and the figures for unification supporters are 2 percent, 8 percent, and 8 percent. $^{24}$

It is easy to understand the reasons for this trend. Although most Taiwanese supported Ma's mainland policy after he was elected in 2008, gradually a large segment of them started to criticize it for going too far in accommodating Beijing without yielding the fruits that he had promised. In the public sphere and especially on the Internet, ethnic representations continued to be debated and promoted. ${ }^{25} \mathrm{~A}$ first indicator of a backlash to the KMT's resinicization plan occurred in late 2011. Then Ma had to drop his idea of starting political negotiations with the PRC after his reelection in 2012 because of the strong opposition of a majority of Taiwanese. KMT leader Wu Bo-hsiung's announcement of the "one country, two areas" formula in March 2012 in China, perceived as too close to the now infamous "one country, two systems" concept, was supported by only 33 percent of Taiwanese (and opposed by 55 percent). ${ }^{26}$ But it was in Ma's second term that tensions started to intensify, reaching their peak when some KMT legislators tried in March 2014 (without, in the view of the DPP, enough parliamentary discussion of its content) to ratify the Cross-Strait Service Trade Agreement (CSTA), which Taipei and Beijing negotiators had signed in June 2013. This calamitous decision precipitated one of the largest civil disobedience mobilizations in democratic Taiwan's history: the twenty-three-day Sunflower Movement protest. While its causes were both multiple and complex, political and socioeconomic, this movement was a clear manifestation of Taiwan's civic identity. Between March and June 2014, the proportion of Taiwanese claiming a Taiwanese identity climbed from 58.2 percent to 60.5 percent. ${ }^{27}$ In other words, Ma’s Chinese nationalism was clearly out of sync with the trends at play in Taiwanese society and contributed to weakening the KMT's discourse and policy toward the mainland as well as strengthening the island's Taiwaneseness. ${ }^{28}$ More importantly, Ma's discourse and policies intensified the frustrations of the Taiwanese, who had already been badly affected by their stagnating standard of living as well as the island's economic slowdown and growing social inequalities. More generally, Ma's Chinese nationalism reduced the chances of the KMT to stay in power after 2016. Turning into a blatant defeat for the KMT and a landslide victory for the DPP, the November 2014 local elections confirmed, among other things, the unpopularity of Ma's Chinese nationalism. So did Tsai's clear victory ( 56 percent of the vote) against KMT candidate Eric Chu Li-luan (31 percent) and People's First Party's James Soong Chu-yu (13 percent) in the January 2016 presidential election, and the emergence from the Sunflower Movement of the New Power Party (shidai liliang) 
on the "Greener" and more proindependence side of the political spectrum (five legislators, 6 percent of the vote).

The consolidation of Taiwan's distinct identity can also be interpreted as part of a reaction against globalization that has taken place around the world, including in Europe. It that sense, it is much less paradoxical than it may appear. Nevertheless, in the case of Taiwan, it also demonstrates that national identity is not shaped by the state (the ROC) but by broader political and social trends such as "the practice of sovereignty through the ballot box and the evolution of multi-party politics in the context of a thriving, pluralistic civil society in which identities shift, interact and compete." ${ }^{29}$ In the Taiwan case, the consolidation of a distinct identity is also a reaction to the PRC's increasing military threat and ability to influence Taiwan's society, business people, media, and elites: in other words, it is a response to as well as an attempt at compensating for and rebalancing the growing asymmetry of cross-Strait relations. ${ }^{30}$

The next question is of course whether Taiwan's assertion of a distinct identity is not due to eventually fail. The asymmetrical integration process between Taiwan and China may already be affecting identity politics and, perhaps more importantly, gradually delinking the existing close relationship between identity and mainland policies.

\section{A DOMINANT BUT CHANGING TAIWANESE IDENTITY}

It is clear that Taiwan is not Hong Kong and that, unlike the former British colony, which has agreed to reintegration in the PRC as long as this occurs within the "one country, two systems" framework, the ROC is a de facto sovereign state whose future cannot be decided without its consent. However, there are some similarities between the two civil societies with regard to their identity politics: both societies are asserting the local versus the global, the protection of their interests in the face of an overwhelming force-the rise of China. ${ }^{31}$ Many young Hong Kong activists went to Taiwan in the summer of 2014 to study from the Taiwanese involved in the occupation of the Legislative Yuan, and some of the latter went to Hong Kong to support the Occupy Central movement. Since the Sunflower Movement in spring 2014 and the subsequent seventy-nine-day Umbrella Movement in Hong Kong in autumn 2014, these similarities between the two movements have become even more striking: both highlight a will to resist and a sense of crisis. ${ }^{32}$ At the same time, another dimension of this crisis is that Taiwan's and Hong Kong's stronger local identities have become more and more disconnected from the options that political parties can offer to their citizens and that individuals, especially young people, can contemplate in terms of life and career.

As far as Taiwan is concerned, since she came into office in May 2016, Ms. Tsai Ing-wen has tried very hard to preserve the status quo in the Strait, and 
this despite Beijing's obvious lack of cooperation and insistence that she endorse the so-called 1992 Consensus. In the run-up to her electoral campaign and during her trip to the United States in June 2015, she had already made clear that, if elected, she would preserve the "status quo," preserve the "ROC constitutional order," and, contrary to Chen Shui-bian, not give any bad "surprises" to Washington or Beijing. ${ }^{33}$ If the DPP has become much more cautious, it is also because Taiwan's society, mind-set, and elites have gradually changed. For instance, it is clear that today an increasing number of young Taiwanese are tempted to start or continue their professional development in China, a place that is much more attractive in terms of both salary and job opportunities than the island, even if a majority of them would prefer staying in Taiwan (40 percent versus 32 percent, according to a recent survey). ${ }^{34}$ Moreover, before 2008, those Taiwanese keen to develop a closer political and functional relationship with the mainland were usually associated with big enterprises or KMT-leaning companies. This is no longer the case: today, a growing number of Taiwanese small businesses, including those in the "Green" South (Kaohsiung, Tainan, Chiayi), have a vested interest in maintaining stable relations with China. For example, their economic reliance on Chinese tourists has become more obvious, particularly since 2012, and the drop in Chinese tourists since early 2016 has led some of them to protest against the new ROC government and even ask it to endorse the 1992 Consensus. As a result, although since Tsai took office she has actively promoted a "New Southbound Policy" aimed at reducing Taiwan's dependence upon China's economy and developing closer links with ASEAN, South Asia, and Australia, Tsai has also clearly indicated that she will not scrap any of the agreements concluded by the Ma administration with Beijing or stop the flow of Chinese tourists visiting Taiwan. And in any event, despite this new policy priority, the level of Taiwan's economic dependency upon China is likely to remain high.

Consequently, Taiwan's identity, while getting stronger, is being increasingly constrained by these realities and gradually disconnected from Taiwan's quest for full statehood, let alone formal independence. While still contributing to protecting Taiwan's political autonomy, Taiwanese identity can no longer protect against the island's asymmetrical dependence upon China. While trying to reduce it, Taiwan must accept and manage this dependence: in other words, Taiwanese identity is becoming more and more "Hongkongized" or constrained by Beijing's "oneChina” principle and request.

To be sure, there are still major differences in identity between Hong Kong and Taiwan, since the latter is a de facto state and a democracy and the former is neither a city-state (despite this new aspiration among a minority of young Hong Kong activists) nor a full democracy. However, it appears that more Taiwanese, particularly youth, have adopted a more relaxed and realistic approach to their 
own identity; it appears also that identity politics is losing steam and may become less of an electoral issue in the future.

\section{Identities and Political Options}

As Taiwanese society is getting more globalized, it is also becoming more diverse. And new forms of postmodern political and cultural expression have contributed to deemphasizing the importance of identity as a whole. For one thing, several studies have shown that young Taiwanese have a more flexible and pragmatic approach to the PRC ${ }^{35}$ : as already mentioned, their professional careers often include at least a temporary relocation to the mainland, since the local employment market remains sluggish and offers less well-paid jobs. In case of war, most would rather flee than face conscription and fight for the survival of the ROC, and they are becoming increasingly open-minded about long-term solutions to the crossStrait conflict, including the prospect of unification. ${ }^{36}$

There is another irony, more cultural, in the rise of Taiwanese identity: the slow erosion of the Minnan language in Taiwan, particularly in the north and the center of the island. While it is still widely used in the electoral campaigns, it tends to be less often spoken or even mastered by young citizens. For instance, Sunflower Movement activists mainly used Mandarin or guoyu among themselves or when negotiating with the authorities. And rather than fighting in the name of Taiwanese identity, this movement was fighting for Taiwan's interests as a whole, as a political community and more particularly for the social strata that have not taken advantage of or have been excluded from the benefits of the emerging crossStrait economic integration. In other words, new social and economic cleavages have to some extent replaced identity differences and clashes. ${ }^{37}$ While some of the social movements that have developed since 2008 have an identity component, they more and more focus on very specific issues, such as the environment (the anti-Fourth Nuclear Plant protest), farmers' protection, human rights (such as the abolition of the death penalty), and gender inequalities. ${ }^{38}$

In this context, it has become harder and less convincing to promote a fully Taiwanese cultural identity. Members of postmodern and globalized societies actually do not see themselves through a unique identity. Today, the features shared by Taiwanese and Chinese cultures are still well recognized and accepted by most Taiwanese as is the dominant influence of Chinese culture in Taiwan, if that culture is understood differently from the official and neoconservative Chinese culture propagated by the communist authorities of the PRC. As a result, only a few militants are still trying to Taiwanize all aspects of the local culture, and an even smaller minority recognize the existence of a Taiwanese race distinct from the Chinese race, on the basis of the large number of intermarriages between Hokkien or Hakka migrants and local aborigines in the past four centuries. In any event, the culture and linguistic diversity of the Native Taiwanese themselves (Hoklo, 
Hakka, and the fourteen recognized aboriginal tribes), a diversity also fed by the presence on the island of around six hundred thousand Southeast Asian workers mainly from the Philippines, Thailand, and Vietnam, prevents the construction of a Taiwanese culture, let alone a Taiwanese nationalism around the still dominant Hoklo subethnic group and its language.

The growing numbers of PRC spouses and other residents in Taiwan and taishang (Taiwanese business people) on the mainland are also having an influence on the Taiwanese people's identity that is not always easy to assess, for there is still a dearth of thorough research on them. ${ }^{39}$ While around 350,000 mainland Chinese spouses have married Taiwanese citizens in the last twenty years or so (roughly 320 ,000 of them reside in Taiwan, the others mainly in the PRC), it is by definition impossible to estimate the total number of PRC nationals living on the island. ${ }^{40}$ The number of illegal PRC nationals is also increasing and difficult to track. Conversely, between one and two million Taiwanese people are living on the mainland, and some of them have married local spouses. In any event, these two distinct but growing communities and their offspring have already started to influence and alter Taiwan's view of the PRC (and China's view of Taiwan), much as mixed marriages and the growing number of mainlanders residing in Hong Kong (10 to 15 percent of the population) have been slowly changing the local social fabric there. The sheer magnitude of these interactions cannot be discounted as marginal, especially in a society whose fertility rate has continuously decreased during the last twenty years (1.12 births per woman in 2016, down from 1.76 in 2000)..$^{4}$ While this phenomenon may not have immediate consequences yet-Taiwan's and Hong Kong's local civic identity has so far continued to consolidate-it is likely to facilitate Beijing's promotion of unification under the formula "one country, two systems" and eventually to modify both places' sense of identity vis-à-vis China.

Studies on the taishang tend to conclude that most Taiwanese people working in China have kept a strong Taiwanese identity. One simple reason is that the bulk of them are native Taiwanese, as opposed to mainlanders, and have tended to stay together, live in the same areas, and speak Hokkien rather than Mandarin among themselves. It can also be argued that the PRC administrative category in which they have been put from the very beginning of the reform era (1979) - "Taiwanese compatriots" equipped with a special identification and travel document, the taibaozheng - has not made them more Chinese but has instead kept them outside local Chinese society, much in the way that Hong Kong business people (who have been equipped since the beginning of the reform era with a "hometown return permit," huixiangzheng) have remained outsiders. While according to estimates around two-thirds of them are inclined to vote for the KMT or Blue camp candidates, the majority still claim a Taiwanese identity (50 percent, compared to 62 percent of those who do not work in China). Though a higher proportion of them claim a dual identity (40 percent compared to 32 percent for those who do 
not work in China), few see themselves as only Chinese (6 percent compared to 4 percent). Moreover, most taishang continue to identify with the ROC, not the PRC; they believe nearly as much as the rest of the Taiwanese population that Taiwan is a "sovereign, independent country" (59 percent vs. 65 percent for those who do not work in China); they remain massively in favor of the status quo in the Taiwan Strait ( 56 percent vs. 59 percent); and they even continue to prefer independence ( 25 percent against 26 percent) to reunification ( 11 percent vs. 6 percent)..$^{42}$ All in all, although the taishang have become what I would call "agents of accommodation," they are not yet, and probably will not become, "agents of unification." ${ }^{43}$

\section{The Decline of Identity Politics}

It is somewhat paradoxical to propose that while a Taiwanese identity has consolidated on the island, identity politics is declining. But there is some logic in this paradox. As most ROC voters were born and have been socialized in Taiwan, the distinction between mainlanders and natives has been gradually losing its pertinence. For a large majority of islanders, Taiwanese identity is now a given.

It is true that in promoting to government and various state agencies a large number of mainlanders $\mathrm{Ma}$, himself a mainlander, was partly responsible for reactivating the debate. But in so doing he also contributed to dividing his own party and alienating Taiwanese KMT leaders. The rift between Ma and Legislative Yuan speaker Wang Jin-pyng, a local Taiwanese and a key mediator in the peaceful end of the Sunflower Movement and the occupation of the Legislative Yuan by some activists, can be seen through that lens. But in the latest elections identity politics has been less of an issue, being sidelined in favor of bread-and-butter, public policy, and social issues. For instance, in the campaign preceding the January 2016 election, while promoting Taiwan's aboriginal roots and multiculturalism, Tsai Ing-wen and the DPP have been keen to avoid reviving identity politics, knowing full well that it is both a risky weapon and an argument that may not appeal to most of the electorate, particularly young voters.

The Ko Wen-je phenomenon also illustrates the receding importance of identity politics in Taiwan. Elected Taipei mayor in November 2014 against KMT candidate Sean Lien Sheng-wen, Lien Chan's son, this surgeon is new to politics and ran as an independent. Although supported by the DPP, he embodies the emergence of a new political force that many Taiwanese, including in the Sunflower Movement, have been hoping for, in order to break the debilitating KMT-DPP and mainlander-native polarization. ${ }^{44}$

This development has forced both the DPP and the KMT to adjust and also if not sideline at least downgrade identity politics. On the DPP side, Tsai Ing-wen has been keener to reassure the electorate about her party's ability to revive the economy and adopt a workable China policy than to emphasize its Taiwaneseness. 
And even independence-leaning politicians and think tanks now recognize the special nature of Taiwan's relation to China. For instance, although critical of Tsai's moderation, dark Green leader Ku Kuan-min proposed in 2013 that both sides of the Strait become "brotherly states" (xiongdi zhi bang), or, more accurately, brotherly entities within the same confederation. ${ }^{45}$

On the KMT side, we perceive a gradual deemphasizing of Chinese identity as a new generation of leaders has taken over, even if Hung Hsiu-chu, the daughter of a mainlander from Zhejiang and a dark Blue leader, became party chair in March 2016. The fact that the KMT replaced Hung as its presidential candidate in October 2015 because of her pro-PRC leanings, just three months after having handpicked her, with New Taipei City mayor Eric Chu, a more popular figure (and KMT chair from January 2015 to January 2016), highlights a willingness to better connect with the electorate and re-Taiwanize the party. Eric Chu has a mixed family background, and the strong Taiwanese identity that he acquired through his father-in-law, his wife, and his mother has helped him: he speaks excellent Hokkien, and Kao Yu-jen, his father-in-law, a local Taiwanese who was promoted in the 1970 and 1980 s by Chiang Ching-kuo (he was the speaker of Taiwan's Provincial Assembly from 1981 to 1989) has close connections both with local KMT and DPP elites. But more importantly, distancing himself from the KMT "unificationists" like Wu Poh-hsiung and "Chinese nationalists" like Ma Ying-jeou or Ms. Hung, Eric Chu has been aware of the need for his party to refocus on social and economic rather than identity issues. For these reasons, it is unlikely that Hung will be able to reunite the Nationalist Party around a credible policy platform and allow it to come back to power.

This decline of identity politics reflects a diversification of the ways to be Taiwanese, the strengthening of local identities in different parts of the island, and to some extent the resilience of multiple identities, an attribute of most postmodern and free societies. As noted above, it also indicates that Taiwanese identity is now taken for granted. In other words, the decline of identity politics is a sign of the maturation and perhaps consolidation of Taiwanese democracy.

\section{CONCLUSION}

Closely linked to the island's democratization and democratic life, Taiwanese identity will probably continue to consolidate while Chinese and even dual identities weaken on this island. The spring 2014 Sunflower Movement and KMT's landslide defeats in both the November 2014 local elections and the January 2016 national elections have to a certain extent illustrated this trend. But at the same time, we are witnessing a diversification of the ways to be Taiwanese. It has led some to associate their identity with the local culture and language and with the building of a new Taiwanese nation de facto if not de jure and forever independent from 
China, while it has led others to accommodate their identity to a democratized, sovereign, and de facto independent ROC on Taiwan, and still others, though a small minority, to envisage a future in which Taiwan is eventually reunified with the mainland (probably after the PRC democratizes) but keeping their Taiwanese cultural identity ${ }^{46}$ The disconnect between identities and political options for the future of Taiwan will probably continue to widen, as most Taiwanese, while attached to their distinct identity, are very much aware that the only viable solution for their country is the ROC institutional envelope, the status quo in the Strait, US informal but reliable protection, and growing communication and cooperation with the PRC. With that said, most Taiwanese now, contrary to the 199os or the early 20oos, identify the ROC with Taiwan and do not countenance any legal inclusion of the mainland in their own polity: ${ }^{47}$ even if they feel partly Chinese, in their eyes, the PRC is another country. In other words, the distinction between state and national identity has clearly disappeared. The Taiwanese civic identity that has emerged today identifies only with the ROC or Taiwan, or with what Lee Teng-hui liked to call in the late 199os the Republic of China on Taiwan: it is therefore, for most Taiwanese, a form of national identity.

For some Taiwanese, their identity will remain holistic, both political and cultural, and will influence all aspects of their life. But this group will probably get smaller as Taiwan is more and more integrated with China but also globalized and divided by deepening social and economic inequalities. As a result, identities and identity politics will lose some of their importance in Taiwan. However, as Taiwan continues to be militarily threatened by the PRC, a power that denies its existence even under its official name, the ROC, and wants to annex it, Taiwanese identity, understood as a political or civic identity, is likely to survive and remain, with democracy, one of the most natural ramparts against Beijing's imperial dream of reunification.

\section{NOTES}

1. Election Study Center, National Chengchi University, "Taiwanese/Chinese Identification Trend Distribution in Taiwan (1992/6-2016/6)," August 24, 2016, http://esc.nccu.edu.tw/course/news. $\mathrm{php}$ ? $\mathrm{Sn}=166$.

2. Some more recent studies have tried to establish a distinction between the two, arguing that "Taiwanese culture is not a significant factor in influencing Taiwanese people's national identity." See Yang Zhong, "Explaining National Identity Shift in Taiwan," Journal of Contemporary China 25, no. 99 (2016): 350 .

3. Transcribed here in the Taiwanese language's accepted but not unique romanization.

4. Wang Fu-chang, "Zuqun yishi, minzuzhuyi, yu zhengdang zhichi: Yijiujiuling niandai Taiwan de zuqun zhengzhi" [Ethnic consciousness, nationalism, and party support: Taiwan ethnic politics in the 1990s], Taiwan shehuixue jikan 2 (1998): 1-45. Shandiren means "mountain people," excludes the "plain" (pingpu) aborigines, supposedly more "assimilated," and is derogatory; yuanzhumin is the correct translation of "aborigines," and this concept was included in the ROC Constitution in 1992. There 
are fourteen recognized groups of yuanzhumin today. In the PRC, the Taiwan aborigines are still called gaoshanzu or "ethnic group of the high mountains" and are considered as a single minority.

5. Shelley Rigger, Politics in Taiwan: Voting for Democracy (London: Routledge, 1999), 19.

6. Christopher Hughes, Taiwan and Chinese Nationalism: National Identity and Status in International Society (New York: Routledge, 1997), 70-94; Yi-huah Jiang, "Is Taiwan a Nation? On the Current Debate over Taiwanese National Identity and National Recognition," in The Dignity of Nations: Equality, Competition and Honor in East Asian Nationalism, ed. Sechin Y. S. Chien and John Fitzgerald (Hong Kong: Hong Kong University Press, 2006), 141-64.

7. Shiau-chi Shen and Nai-teh Wu, "Ethnic and Civic Nationalisms: Two Roads to the Formation of a Taiwanese Nation," in The "One China" Dilemma, ed. Peter Chow (New York: Palgrave Macmillan, 2008), 117-46; Frank Muyard, "The Formation of Taiwan's New National Identity since the End of the 1980s," in Taiwan since Martial Law: Society, Culture, Politics, Economy, ed. David Blundell (Berkeley: University of California, Berkeley; Taipei: National Taiwan University Press, 2012), 297-366.

8. A civic identity can emerge in any kind of political community, be it national or subnational; it does not necessarily coincide with a national identity. For instance, Hongkongers have a strong civic identity, but the large majority of them still identify with China.

9. Jean-Pierre Cabestan, "Specificities and Limits of Taiwanese Nationalism," China Perspectives, no. 62 (November-December 2005): 32-43.

10. Rou-lan Chen, "Beyond National Identity in Taiwan: A Multidimensional and Evolutionary Conceptualization," Asian Survey 52, no. 5 (2012): 845-71.

11. The "Huangpu spirit" still strongly influences the ROC armed forces; the KMT based it on the ethos of the Huangpu (or Whampoa) Military Academy, created by Sun Yat-sen in 1924 in one of Guangzhou (Canton)'s districts. This army academy (lujun guanxiao) trained the officers that would lead in 1926-27 the "Northern Expedition" and unify China under the KMT regime, based in Nanking. After 1949, the ROC military academy was relocated in Fengshan, near Kaohsiung.

12. Stéphane Corcuff, ed., Memories of the Future: National Identity Issues in the Search for a New Taiwan (Armonk, NY: M.E. Sharpe, 2002); Christopher R. Hughes, "Negotiating National Identity in Taiwan: Between Nativisation and Desinicisation," in Taiwan's Democracy: Economic and Political Challenges, ed. Robert Ash, John W. Garver, and Penelope Prime (London: Routledge, 2011), 51-74.

13. J. Bruce Jacobs and I-hao Ben Liu, "Lee Teng-hui and the Idea of 'Taiwan," China Quarterly 190 (June 2007): 375-93.

14. Election Study Center, "Taiwanese/Chinese Identification Trend."

15. Shen and Wu, "Ethnic and Civic Nationalisms."

16. Shi Ming, Taiwanren sibai nian shi [Four hundred years of history of the Taiwanese] (1962; repr., Taipei: Huacao wenhua, 1998).

17. Cabestan, "Specificities and Limits."

18. Hughes, "Negotiating National Identity," 69-71.

19. Christopher R. Hughes, "Revising Identity Politics under Ma Ying-jeou," in Political Changes in Taiwan under Ma Ying-jeou: Partisan Conflict, Policy Choices, External Constraints and Security Challenges, ed. Jean-Pierre Cabestan and Jacques deLisle (London: Routledge, 2014), 120-36.

20. Ma Ying-jeou, Yuanxiang jinshen: Taiwan de dianfan gushi [Native spirit: The model story of Taiwan] (Taipei: Tianxia yuanjian chuban, 2007). A Chinese official close to Li Hongzhang, Liu Mingchuan was appointed in 1885 as governor of the newly created Taiwan Province (before it was a prefecture of Fujian Province). He played an important role in the modernization and the defense of the island. He resigned in 1891 for health reasons.

21. In 2010, Liu Fu-kuo (a National Cheng Chi University Institute of International Relations research fellow) and Wu Shicun (president of the Chinese National Institute for South China Sea Studies) cohosted a project that produced policy proposals recommending that Taiwan and China join forces to protect the territory of "one China" and that cross-Strait military and political cooperation 
be implemented in the South China Sea; DPP legislator Chen Chi-mai claimed that the Taiwanese Foreign Ministry had endorsed Liu's project, but the ministry denied this. Taipei Times, June 8, 2015. See also on this issue J. Michael Cole's "Taiwanese Academics Are Playing with Fire," Thinking Taiwan, May 29, 2014, http://thinking-taiwan.com/taiwanese-academics-are-playing-with-fire/; Liu Fu-kuo and Wu Shicun, eds., 2010 Nian nanhai diqu xinshi pinggu baogao [Report on the assessment of the status of the South China Sea area in 2010] (Taipei: Institute of International Relations, Chengchi University, 2010).

22. Stéphane Corcuff, "Ma Ying-jeou's China Leaning Policy and the 1683 Fall of the Zheng in Taiwan: A Cross-centuries Geopolitical Comparison," in National Identity and Economic Interest: Taiwan's Competing Choices and Their Implications for Regional Stability, ed. Peter Chow (New York: Palgrave Macmillan, 2011), 93-134; Hughes, "Revising Identity Politics," 123.

23. André Beckershoff, "The KMT-CCP Forum: Securing Consent for Cross-Strait Rapprochement," Journal of Current Chinese Studies 43, no. 1 (2014): 213-41.

24. Taiwan Brain Trust, 2014 Taiwan Brain Trust Trend Survey (Taipei: New Taiwan Peace Foundation and Taiwan Brain Trust, 2014), en.braintrust.tw/userfiles/images/Trend/201412TBTsurvey.pdf.

25. Jens Damm, "Taiwan's Ethnicities and Their Representation on the Internet," Journal of Current Chinese Affairs 40, no. 1 (2011): 99-131.

26. Hughes, "Revising Identity Politics," 130.

27. Taiwan Brain Trust, 2014 Taiwan Brain Trust Trend Survey. This result was confirmed by Election Study Center, "Taiwanese/Chinese Identification Trend."

28. Syaru Shirley Lin, Taiwan's China Dilemma: Contested Identities and Mutliple Interests in Taiwan's Cross-Strait Economic Policy (Stanford, CA: Stanford University Press, 2016).

29. Hughes, "Revising Identity Politics," 131.

30. Chien-jung Hsu, The Construction of National Identity in Taiwan's Media, 1986-2012 (Leiden: Brill, 2014).

31. Malte Phillip Keating, "Identity Formation in Taiwan and Hong Kong: How Much Difference, How Many Similarities?", in Taiwanese Identity in the Twenty-First Century: Domestic, Regional and Global Perspectives, ed. Gunter Schubert and Jens Damm (Abingdon: Routledge, 2011), 258-80.

32. Syaru Shirley Lin, "Bridging the Chinese National Identity Gap: Alternative Identities in Hong Kong and Taiwan," in the "National Identity Approaches to East and South Asia" section of Joint USKorea Academic Studies, vol. 25, ed. Gilbert Rozman (Washington, DC: Korea Economic Institute of America, 2014), 113-32, www.keia.org/sites/default/files/publications/syaru_shirley_lin.pdf.

33. Tsai Ing-wen, "Taiwan Meeting the Challenges, Crafting a Model of New Asian Value," speech to the Center for Strategic and International Studies (CSIS), Washington DC, June 3, 2015, http://english.dpp.org.tw/dr-tsai-ing-wen-speaks-at-center-for-strategic-and-international-studies/.

34. China Youth Corps Survey, quoted in Taipei Times, March 25, 2015, 3.

35. Shelley Rigger, Taiwan's Rising Rationalism: Generations, Politics, and « Taiwanese Nationalism (Washington, DC: East-West Center, 2006), 44.

36. Tanguy Le Pesant, "Generational Change and Ethnicity among 1980s-Born Taiwanese," Journal of Current Chinese Affairs 40, no. 1 (2011): 133-57; Tanguy Le Pesant, "A New Generation of Taiwanese at the Ballot Box," China Perspectives 2 (2012): 71-79.

37. Jonathan Sullivan, "Taiwan's Identity Crisis: The Conundrum for the DPP Is That the Taiwanese Identity That Has Been Trampled On and Discarded under Ma Is Both a Trump Card and a Liability," National Interest, August 18, 2014, http://nationalinterest.org/feature/taiwans-identity-crisis-11093.

38. Min-sho Ho, "The Resurgence of Social Movements under the Ma Ying-jeou Government: A Political Opportunity Structure Perspective," in Cabestan and deLisle, Political Changes in Taiwan, $100-119$.

39. A useful exception is Gunter Schubert, "The Political Thinking of the Mainland Taishang: Some Preliminary Observations from the Field," Journal of Current Chinese Affairs 39, no. 1 (2010): 73-110. 
40. "320,000 Chinese Married to Taiwanese: Agency," China Post, April 29, 2013, www.chinapost. com.tw/taiwan/national/national-news/2013/04/29/377256/3200oo-chinese.htm; "Most High Income Chinese Couples Want a Second Child," Women of China, February 17, 2014, www.womenofchina.com. $\mathrm{cn} / \mathrm{html} / \mathrm{report} / 6834-1 . \mathrm{htm}$.

41. Index Mundi, "Total Fertility Rate: Children Born/Woman," Taiwan, www.indexmundi.com/ g/g.aspx? $c=t w \& v=31$ (accessed November 1, 2016).

42. Taiwan Brain Trust, 2014 Taiwan Brain Trust Trend Survey.

43. Chun-Yi Lee, Taiwanese Business or Chinese Security Asset: A Changing Pattern of Interaction between Taiwanese Businesses and Chinese Governments (London: Routledge, 2011); Shu Keng and Gunter Schubert, "Agents of Unification? The Political Role of Taiwanese Businessmen in the Process of Cross-Strait Integration," Asian Survey 50, no. 2 (2010): 287-310. Lee is more pessimistic than Schubert or Keng about the taishang's chances of not being influenced by the political and ideological environment in which they live.

44. Frank Muyard, "Voting Shift in the November 2014 Local Elections in Taiwan," China Perspectives 1 (2015): 60 .

45. Ku Kuan-min, Xiongdi zhi bang: Taiwan yu zhongguo guoji zouyi [Brotherly states: A brief discussion on relations between Taiwan and China] (Taipei: Taiwan Brain Trust, 2013).

46. Zhong, "Explaining National Identity Shift."

47. On their attitudes in the 1990 s and 200os, see Jiang, "Is Taiwan a Nation?" 